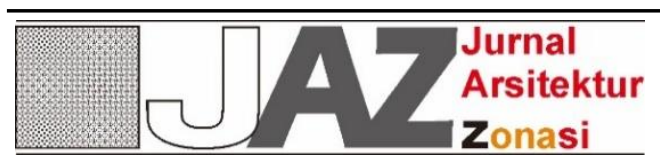

http://ejournal.upi.edu/index.php/jaz - e-mail: jurnal.zonasi@gmail.com dan jurnal zonasi@upi.edu doi.org/10.17509/jaz.v2i3.17857

\title{
PENERAPAN KONSEP INTEGRASI ANTAR RUANG PUBLIK PADA REDESAIN STASIUN KERETA API PATI
}

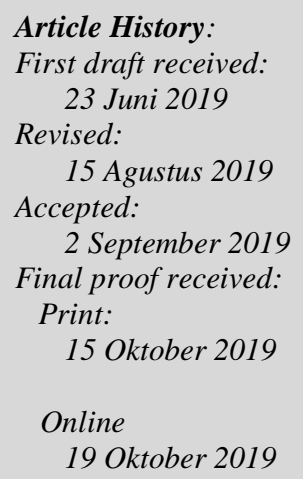

\author{
Ardi Helmi Aziz ${ }^{1}$; Desrina Ratriningsih ${ }^{2}$ \\ 1,2 Program Studi Arsitektur, Faultas Sains dan Teknologi, Universitas Teknologi Yogyakarya, \\ Yogyakarta, Indonesia \\ Jl. Glagahsari No.63, Kec. Umbulharjo, Kota Yogyakarta, Daerah Istimewa Yogyakarta, \\ 55164 \\ Email: ardihelm@gmail.com; desrina@uty.ac.id
}

\begin{abstract}
Pati Train station is one of the second class stations in Pati Regency. Its presence is very helpful in transportation activities between regions within provinces and between provinces. Train station has an important role in relation to mobility of society. But in reality, train stations often lack adequate facilities such as the lack of large waiting rooms, of seats for resting passengers, and of other supporting facilities. Pati Train Station is redesigned on the basis of activation planning for Semarang-Lasem Railway by the Indonesian Railways (PT KAI). In the future, the station's redesign improves the old station by exploring the facts and issues occuring in the field so that the two factors are used as the basis for the design. The concept of "public spaces integration" used in station redesign aims to make it easier for users to get connected to public spaces inside and outside Pati train station. The method used is descriptive method, carried out by collecting primary and secondary data relating to the design object and then analyzing data based on public space theory which is then used as a design solution in the concept of public spaces integration.
\end{abstract}

Keywords: station; train; Pati; integration; public space

\begin{abstract}
Abstrak: Stasiun kereta api Pati adalah satu dari beberapa stasiun kelas dua yang berada di Kabupaten Pati. Keberadaan stasiun ini sangat membantu dalam kegiatan transportasi antar daerah baik di dalam propinsi maupun antar propinsi. Stasiun kereta api memiliki peranan penting yang berkaitan dengan mobilitas masyarakat. Namun, dalam kenyataannya, fasilitas yang terdapat di stasiun kurang memadai dan belum memenuhi standar. Stasiun kereta api Pati di redesain dengan dasar perencanaan aktivasi jalur kereta api Semarang-Lasem oleh Perkeretaapian Indonesia (PT KAI). Pada nantinya redesain stasiun ini memperbaiki stasiun yang lama dengan menggali fakta dan issu yang terjadi di lapangan sehingga menjadikan kedua faktor tersebut sebagai dasar pemikiran perancangan. Konsep "Integrasi Antar Ruang publik" yang digunakan pada redesain stasiun ini bertujuan untuk memudahkan pengguna agar terhubung/terkoneksi ke ruang publik yang ada di dalam stasiun dan luar stasiun kereta api Pati. Metode yang digunakan yaitu metode deskriptif, dilaksanakan dengan mengumpulkan data-data primer dan sekunder yang berkaitan dengan objek perancangan kemudian melakukan analisa data berdasar teori ruang public yang kemudian digunakan sebagai solusi perancangan dalam konsep integrasi antar ruang publik.
\end{abstract}

Kata kunci: stasiun; kereta api; Pati; integrasi; ruang publik

\section{Pendahuluan}

Kereta api adalah salah satu moda transportasi darat yang diminati oleh seluruh lapisan masyarakat. Dengan semakin banyaknya masyarakat yang menggunakan jasa transportasi angkutan darat, sebaiknya diimbangi oleh fasilitas-fasilitas yang memadai seperti perencanaan dan perancangan atau reaktivasi jalur kereta api serta peningkatan pelayanan yang baik, agar masyarakat percaya dan memilih menggunakan jasa transportasi kereta api. Keberadaan stasiun merupakan bagian terpenting dalam perkeretaapian sebagai tempat pemberangkatan dan penurunan penumpang, serta dalam proses interaksi dan aktivitas bagi pengguna jasa transportasi. 
Di dalam Rencana Induk Perkeretaapian Nasional (RIPNAS) tahun 2011(Ditjen Perkeretaapian, 2011), tertuang rencana pengembangan jaringan layanan kereta api di Pulau Jawa pada tahun 2030 khususnya reaktivasi jalur kereta api Semarang-Lasem. Hal ini tentunya disambut dengan antusias oleh masing-masing kepala daerah karena berdasarkan hal tersebut maka sudah pasti beberapa stasiun yang dulunya merupakan tempat pemberhentian dan pemberangkatan kereta api di masing-masing daerah akan diaktifkan kembali. Di dalam Peraturan Daerah Kabupaten Pati no 5 tahun 2011(Pati, 2011) pasal 22 memuat adanya rencana pengembangan sistem prasarana perketaapian, yaitu pengembangan sistem kereta api antar kota yang menghubungkan Semarang-Demak-Kudus-Pati-Rembang, oleh karena itu, guna mendukung pengembangan sistem tersebut, maka direncanakan revitalisasi Stasiun Pati dan Stasiun Juwana. Bupati Pati, Haryanto optimis ketika jalur kereta api Pati dapat dihidupkan kembali akan menjadi jalur potensial yang dapat meningkatkan perekonomian di Wilayah Pati.("Pati Ingin Jalur KA Semarang-Lasem Dihidupkan Lagi," 2019)

Stasiun Kereta Api Pati adalah stasiun kelas I yang sekarang dalam kondisi non aktif atau tidak beroperasi. Terletak di tengah kota Pati, stasiun Pati dahulu adalah stasiun kereta api besar yang melayani masyarakat sekitar Kabupaten Pati. Dibangun pada tahun 1885, stasiun ini milik perusahaan kereta api swasta Hindia Belanda yaitu Semarang-Joana Stoomtram Maatschappij(SJS). Jalur kereta api ini ditutupkarena munculnya kendaraan beroda. Posisi rel kereta api yang berada tepat di pinggir jalan raya harus ditutup karena peningkatan jumlah pengguna kendaraan yang cukup pesat pada tahun 1987. Dengan rencana yang sudah dijadwal oleh Perkeretaapian Indonesia (PT KAI) yaitu reaktivasi jalur kereta api Semarang-Lasem dalam RIPNAS 2030(Ditjen Perkeretaapian, 2011) dipastikan Stasiun yang terlewati jalur akan aktif kembali.

Redesain stasiun kereta api Pati merupakan opsi untuk dikembangkan menjadi sebuah stasiun yang akan membawa dampak perubahan untuk masyarakat kabupaten Pati di masa yang akan datang. Redesain stasiun ini akan mempertimbangkan kemudahan dalam hal akses jangkauan antar ruang publik dalam stasiun dan luar stasiun, maka dipilihlah pendekatan Integrasi antar ruang publik yang akan menjadi konsep redesain stasiun kereta api Pati. Masa revolusi industri 4.0 menjadi hal yang tak dapat dipungkiri dengan segala kemudahan akses yang didapat di masa sekarang dan mendatang baik dari segi sumber daya dan teknologi. Stasiun dengan konsep integrasi ini akan menghilangkan mindset masyarakat tentang susahnya jangkauan dari tempat satu ke tempat yang lain untuk transportasi publik. Integrasi antar ruang publik dalam konsep stasiun ini adalah memanjakan pengunjung stasiun dengan kemudahan yang didapat dalam stasiun dimana tempat dan ruang-ruang yang terhubung/terkoneksi satu sama lain, integrasi ini tidak hanya ada di dalam stasiun tetapi juga luar stasiun dengan pedestrian yang langsung terhubung dengan stasiun. Konsep Integrasi ini memprioritaskan kemudahan akses yang terhubung langsung dengan ruang-ruang publik stasiun baik dalam ataupun luar stasiun.

\section{Metode Penelitian}

Metode yang digunakan yaitu metode deskriptif, dilaksanakan dengan mengumpulkan data-data primer dan sekunder yang berkaitan dengan objek perancangan kemudian melakukan analisa data untuk memperoleh konsep perencanaan dan perancangan. Data yang dikumpulkan meliputi studi pustaka, observasi lapangan untuk mengetahui tapak eksisting, studi banding dan analisis berdasarkan teori integrasi antar ruang publik. Selain itu, pendapat para ahli, atau peraturan dan kebijakan pemerintah tentang perancangan bangunan sehingga mampu menganalisis secara lebih dalam.

\section{Hasil dan Pembahasan}

\subsection{Lokasi Site}

Lokasi Stasiun Kereta Api Pati terletak di tengah kota Pati tepatnya di Puri, Pati. Stasiun ini bersebelahan dengan GOR, pujasera, dan taman kota. Luas sitenya 2,7 Ha milik PT KAI. 

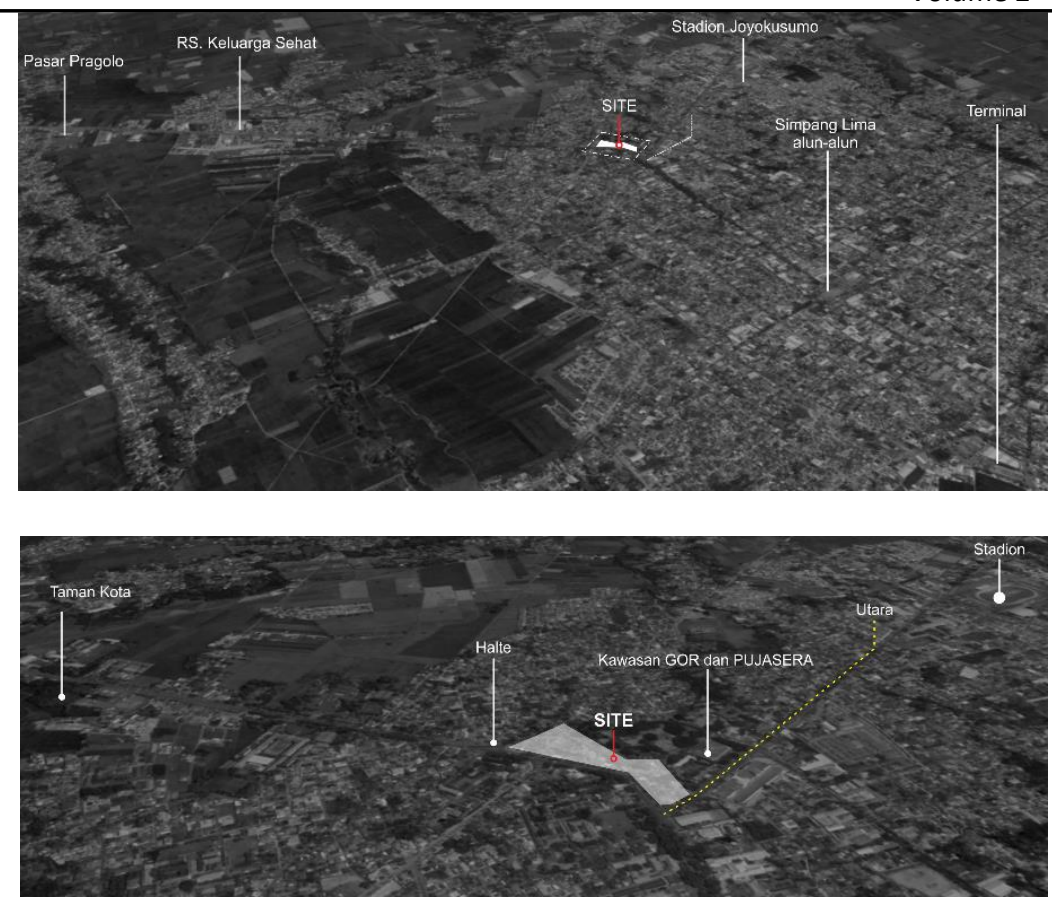

Gambar 1 dan 2. Kondisi Sekitar Site

Sumber: Aziz, 2019

\subsection{Tinjauan Integrasi Antar Ruang Publik}

Ruang publik adalah ruang yang dapat diakses oleh siapa saja sehingga menjadi ruang yang dimiliki oleh seluruh kalangan tanpa ada batasan waktu dan aktivitas.(Hantono, Sidabutar, dan Hanafiah, 2018). Pengertian lain Ruang publik menurut Eko Budihardjo adalah ruang yang berfungsi sebagai wadah untuk menampung aktivitas manusia (Herutomo, 2002). Sedangkan menurut Carr ruang publik adalah ruang dimana masyarakat atau pengguna dapat melakukan kegiatan fungsional (Farida, Yudana, dan Rini, 2017).

Suatu tempat/area dapat dikatakan menjadi sebuah ruang publik yang didalamnya terdapat akses yang juga merupakan ruang terbuka. Akses pada suatu tempat/area haruslah aman dan nyaman untuk dilewati pengunjung.

Carr menyebutkan bahwa suatu ruang publik harus memiliki 3 kriteria, yaitu responsive, democratic dan meaningfull (Ratriningsih, 2017). Democratic berarti melindungi hak-hak kelompok pengguna, dimiliki bersama dengan berbagai latar belakang social, ekonomi dan tentunya dapat dilalui oleh pengguna berkebutuhan khusus. Responsive, yang berarti desain ruang publik harus terencana dan terkelola agar dapat memenuhi segala aktivitas pengguna. Meaningful, yang menjadikan orang/pengguna terhubung kuat dengan tempat tersebut, dengan kehidupan pribadinya dan dengan dunia yang lebih luas dalam konteks fisik \& sosial.

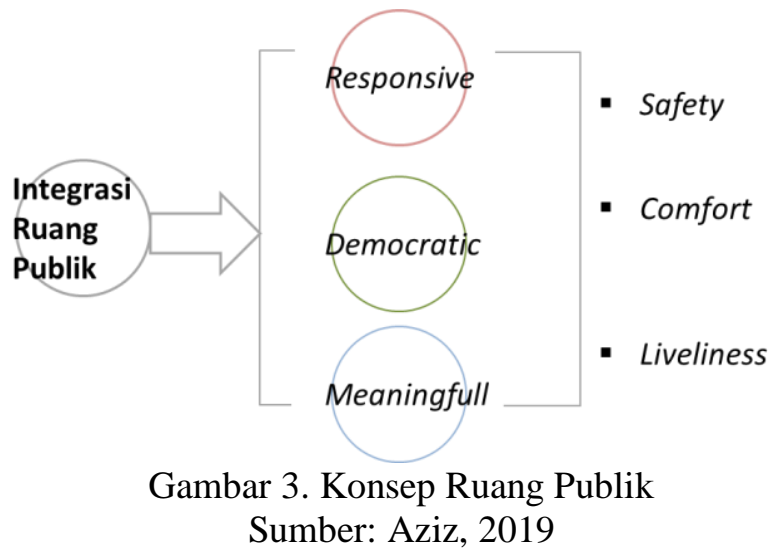

Selain itu, suatu ruang publik harus memenuhi syarat antara lain; Safety, ruang publik harus aman dari segala macam hal yang mengganggu. Liveliness, yang berarti kondisi ruang akan dikatakan berhasil apabila ruang tersebut itu hidup sesuai dengan fungsi kawasan. Comfort, harus ada pula kenyamanan dalam hal 
kelaluasaan gerak, dari material jalan yang dipijak, kejelasan rambu atau penanda jalan hingga perindang yang sangat dibutuhkan bagi pengguna (Ratriningsih, 2017)(Ratriningsih, 2017). Selain itu, Carmona menjelaskan bahwa Comfort adalah kebutuhan dasar, memerlukan makanan, minuman, dan shelter saat diperlukan(Carmona, Matthew, 2007).

Integrasi merupakan pembauran sesuatu yang tertentu hingga menjadi kesatuan yang utuh dan bulat. Dalam hal ini, untuk dapat memberikan kenyamanan mobilitas (Ischak, Setioko, dan Gandarum, 2018) bagi pengguna kereta api harus mempertimbangkan interaksi dan integrasi berbagai fungsi dalam stasiun(Kbbi.kemdikbud.go.id, n.d.).

Ruang publik sebagai bangian utama dari sebuah kota harus memiliki akses dan jaringan yang terbuka bagi semua pihak, suatu ruang publik sebaiknya didesain dengan baik (positif), jelas atau terarah, dan ternaungi(Wirasmoyo, 2019). Beberapa tinjauan mengenai integrasi antar ruang publik ini nantinya akan diterapkan pada redesain stasiun kereta api untuk menunjang kegiatan didalamnya, antara lain:

1. Aktivitas di trotoar merupakan ruang publik yang nantinya akan di integrasikan dengan stasiun.

2. Pengintegrasian antara halte bus yang dekat dengan stasiun untuk menunjang pengguna kereta api.

3. Kegiatan di taman kota dan stadion yang dekat dengan stasiun, mulai dari suporter dan pengunjung taman.

\subsection{Konsep Desain}

\section{Konsep Integrasi Ruang Publik}

Konsep yang di terapkan pada Stasiun Kereta Api Pati adalah Integrasi Antar Ruang Publik yang memudahkan pengunjung stasiun untuk memncapai area-area publik baik di dalam stasiun ataupun di luar stasiun.

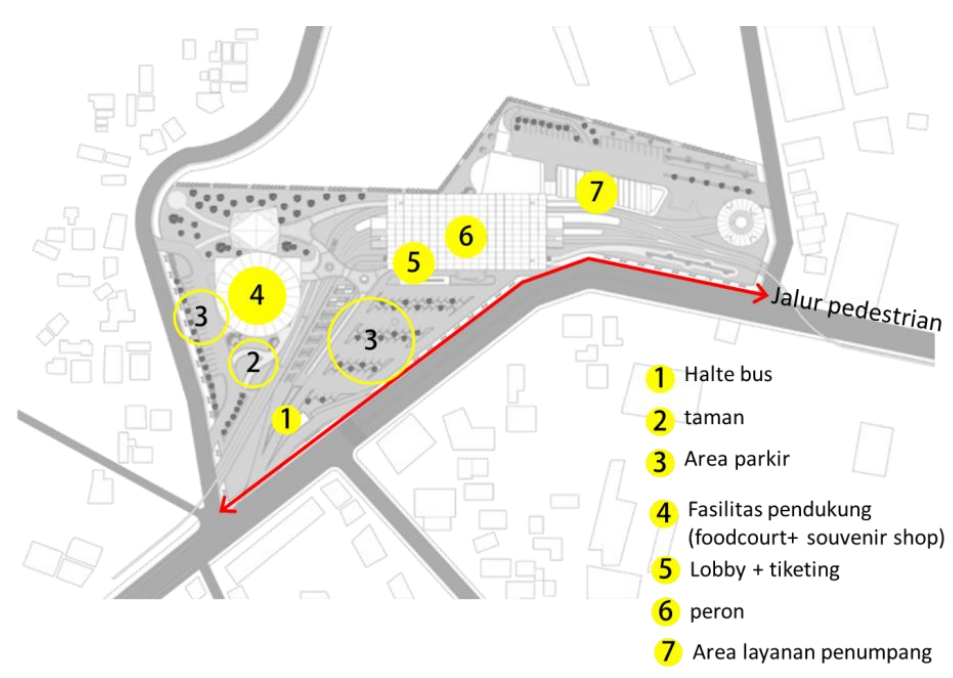

Gambar 4. Ruang Publik di Stasiun Pati

Sumber: Aziz, 2019

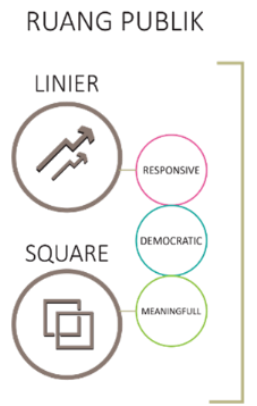

1 Halte bus

2 taman

3 Area parkir

4 Fasilitas pendukung

INTEGRASI (foodcourt+ souvenir shop)

5 Lobby + tiketing

6 peron

7 Area layanan penumpang

Gambar 5. Penerapan Konsep Integrasi Ruang Publik Sumber: Aziz, 2019

Integrasi antar ruang publik di Stasiun Pati dapat dicapai Membuat akses ke dalam tapak yang dapat meminimalisir antrian kendaraan dan membedakan akses pengunjung dengan pengelola 
stasiun. Agar tujuan dari masing-masing pengunjung dan pegawai mudah tercapai dengan effisien dan nyaman ke tempatnya.

Ruang publik yang responsive pada redesain ini diterapkan pada sirkulasi kendaraan untuk pengunjung stasiun dan juga pejalan kaki yang diharapkan dapat memudahkan untuk akses ke stasiun dengan aman dan nyaman. Ruang publik yang democratic ini diterapkan pada area fasilitas pendukung antara lain taman, masjid foodcourt dan oleh-oleh diharapkan penerapan konsep democratic ini memberikan fasilitas yang dapat digunakan untuk umum tidak hanya pengunjung yang akan naik kereta api serta meningkatkan sosial,ekonomi dan budaya masyarakat sekitar. Pada penerapan democratic ini juga memikirkan akses untuk difabel desain akan memakai standar yang dibutuhkan untuk difabel tanpa mendiskriminasi. Ruang publik yang meaningful diterapkan pada desain akses skybridge salah satu keunggulan pada redesain stasiun ini, akses skybridge didesain untuk terintegrasinya fasilitas pendukung dengan stasiun yang dapat memberikan makna dan keterkaitan pengunjung pada redesain stasiun kereta api Pati ini.

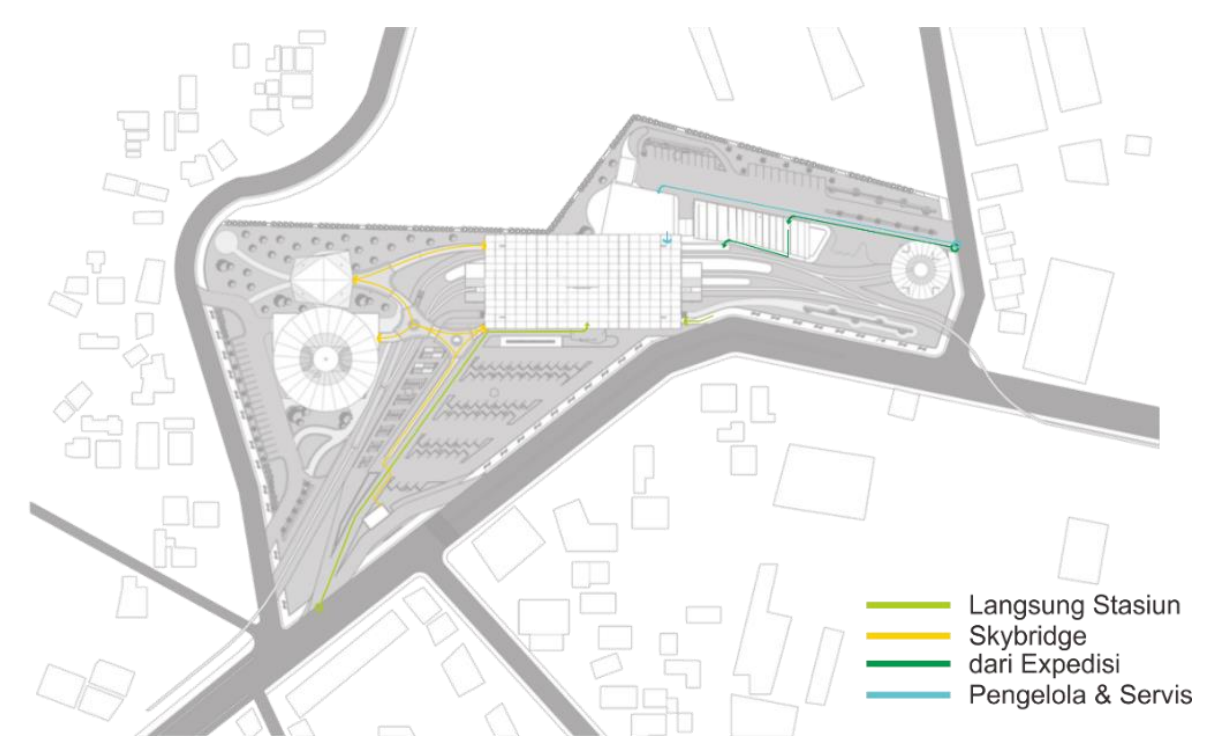

Gambar 6. Konsep Integrasi pada Aksesibilitas Sumber: Aziz, 2019

Akses pengunjung stasiun yang langsung menuju bangunan stasiun dapat dicapai dengan dua akses seperti pada gambar 5 yaitu simbol garis berwarna hijau muda dan simbol garis berwarna orange. Untuk simbol hijau muda pengunjung langsung ke stasiun melalui drop off kendaraan dan juga pejalan kaki dari trotoar, bedanya dengan jalur berwarna orange/skybridge pengunjung yang berkeinginan untuk istirahat, sholat, makan dan membeli oleh-oleh terkoneksi langsung dengan foodcourt, oleh-oleh dan masjid. Tentunya skybridge ini terintegrasi langsung dengan stasiun. Akses expedisi barang adalah akses pengunjung stasiun yang akan mengirim dan membawa barang untuk ditempatkan pada gudang barang akses ini juga terhubung langsung dengan stasiun dapat dilihat pada simbol garis berwarna hijau tua pada gambar 5 . Untuk akses pengelola pada gambar 5 dengan simbol garis berwarna biru dimana akses lebih menjorok kedalam dari akses expedisi barang guna privasi dan keamanan pegawai akses pengelola ini pun terintegrasi langsu dengan stasiun dengan bangunan yang berdekatan.

\section{Konsep Zonasi}

Konsep Zonasi pada stasiun kereta api Pati dibedakan menjadi beberapa bagian zonasi dengan fungsi yang berbeda agar memudahkan kegiatan yang berlangsung distasiun. Ruang pengelola dan servis diletakkan di sebelah timur agar ruangan lebih privasi dan tidak dijangkau oleh pengunjung. Sedangkan area fasilitas pendukung akan diletakkan di sisi barat sebrang rel kereta api agar memudahkan desain akses pengunjung yang akan terintegrasi langsung dengan bangunan stasiun utama. 


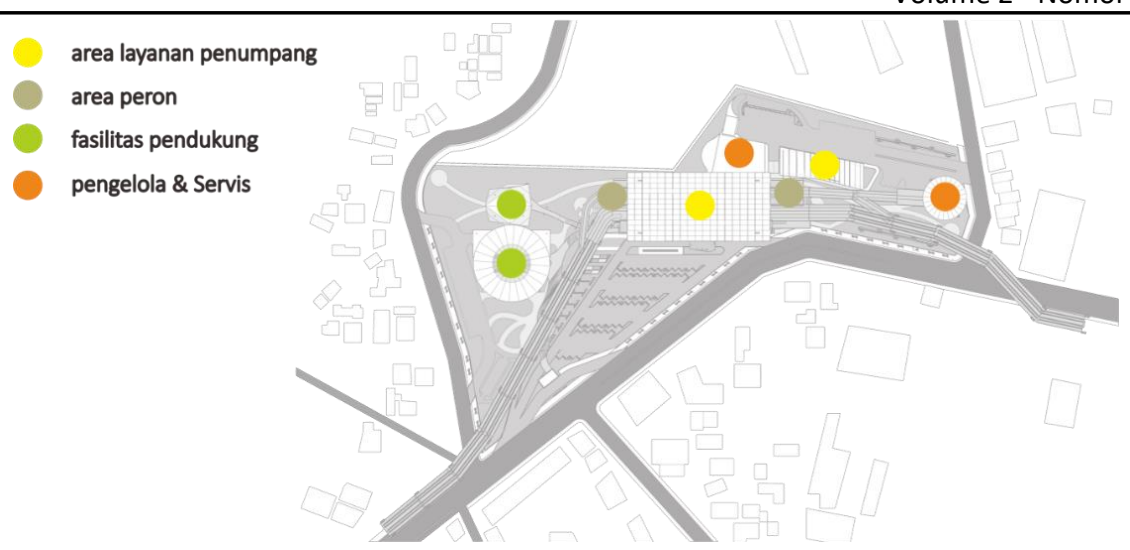

Gambar 7. Konsep Zonasi

Sumber: Aziz, 2019

\section{Konsep Vegetasi dan Material}

Vegetasi digunakan sebagai barrier dan pengatur intensitas cahaya matahari, angin dalam site dan kebisingan keluar bangunan dan juga sebagai petunjuk arah dengan penataan vegetasi yang menuntun pengunjung langsung menuju tempat tujuan. Jenis vegetasi yang digunakan adalah jenis pohon dengan daun yang lebat atau pohon perindang, antara lain:

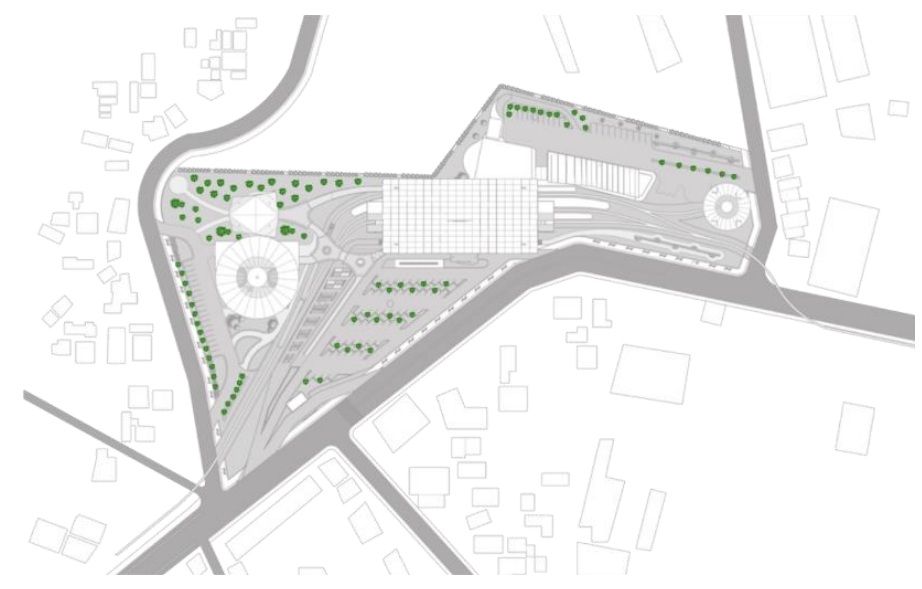

Gambar 8. Konsep Vegetasi

Sumber: Aziz, 2019

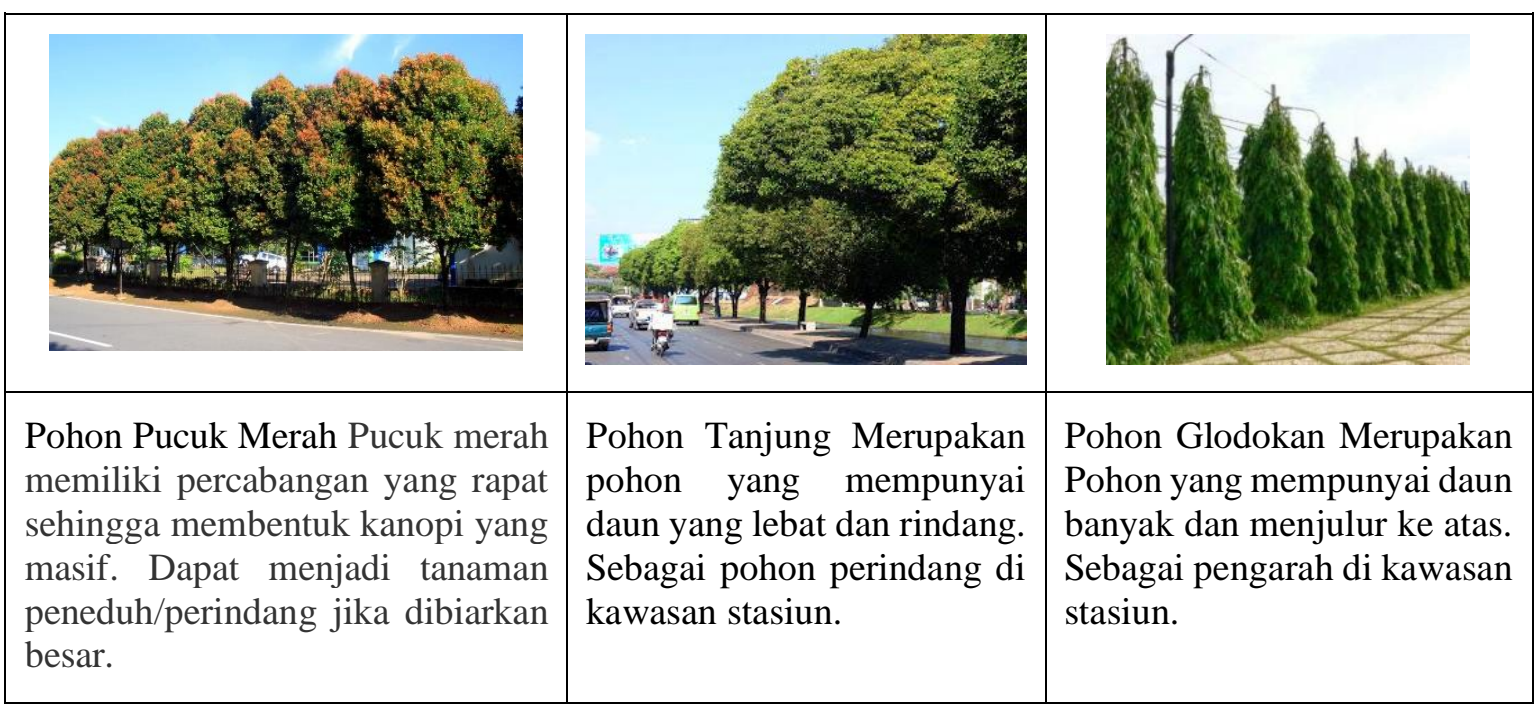




\subsection{Hasil Desain}

Desain yang dibuat dalam Penerapan Konsep Integrasi Antar Ruang Publik pada Redesain Stasiun Kereta Api Pati adalah membuat suatu desain yang telah disesuaikan dari latar belakang masalah dan diselesaikan dengan pendekatan melalui beberapa metode perancangan, sehingga menciptakan suatu desain yang dapat mengatasi permasalahan dan kebutuhan yang ada.

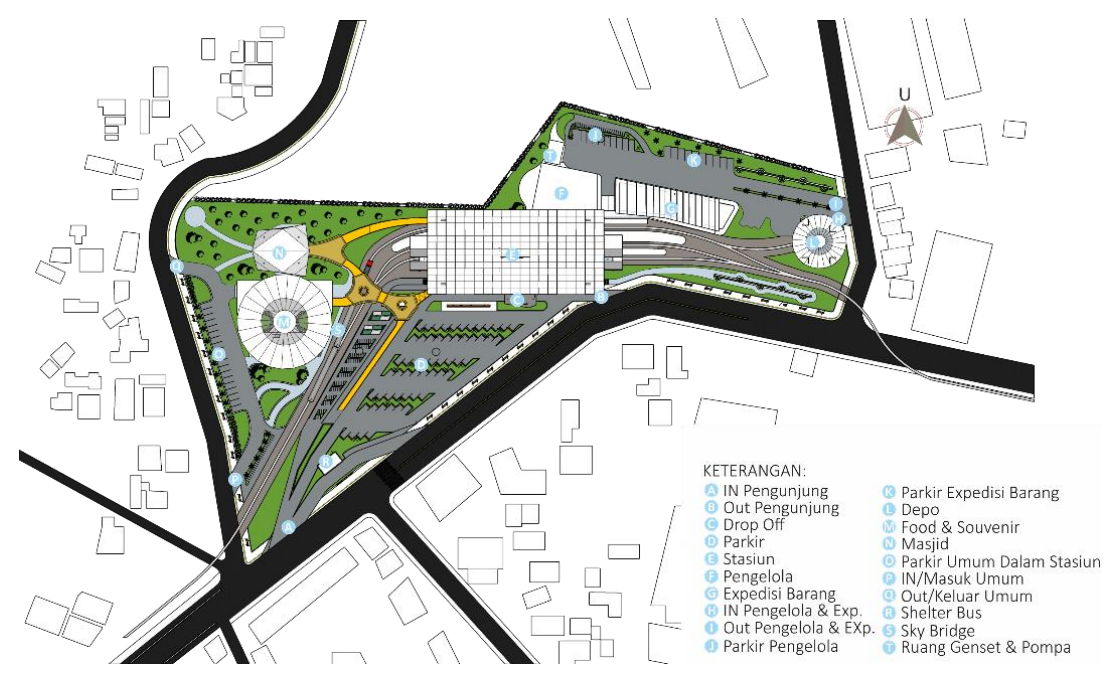

Gambar 8. Situasi

Sumber: Aziz, 2019

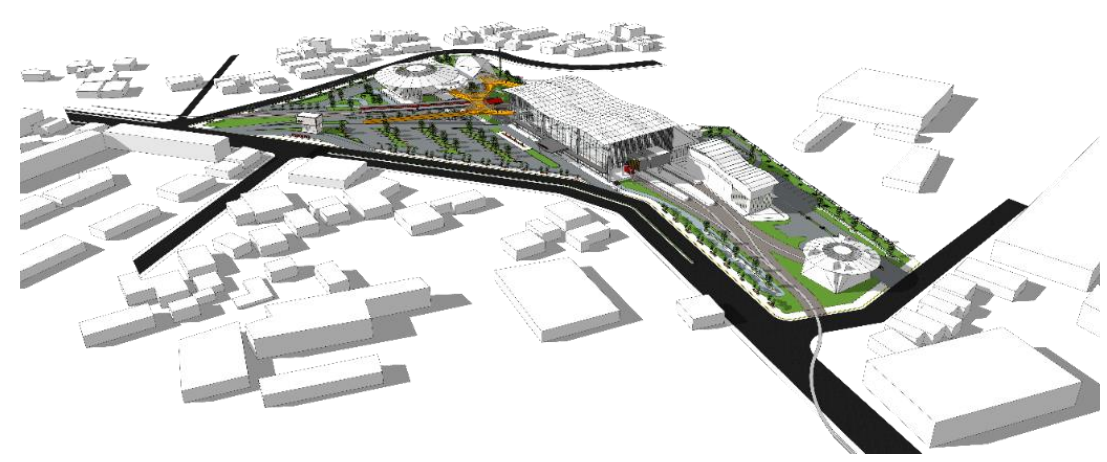

Gambar 9. Perspektif Aerial View

Sumber: Aziz, 2019
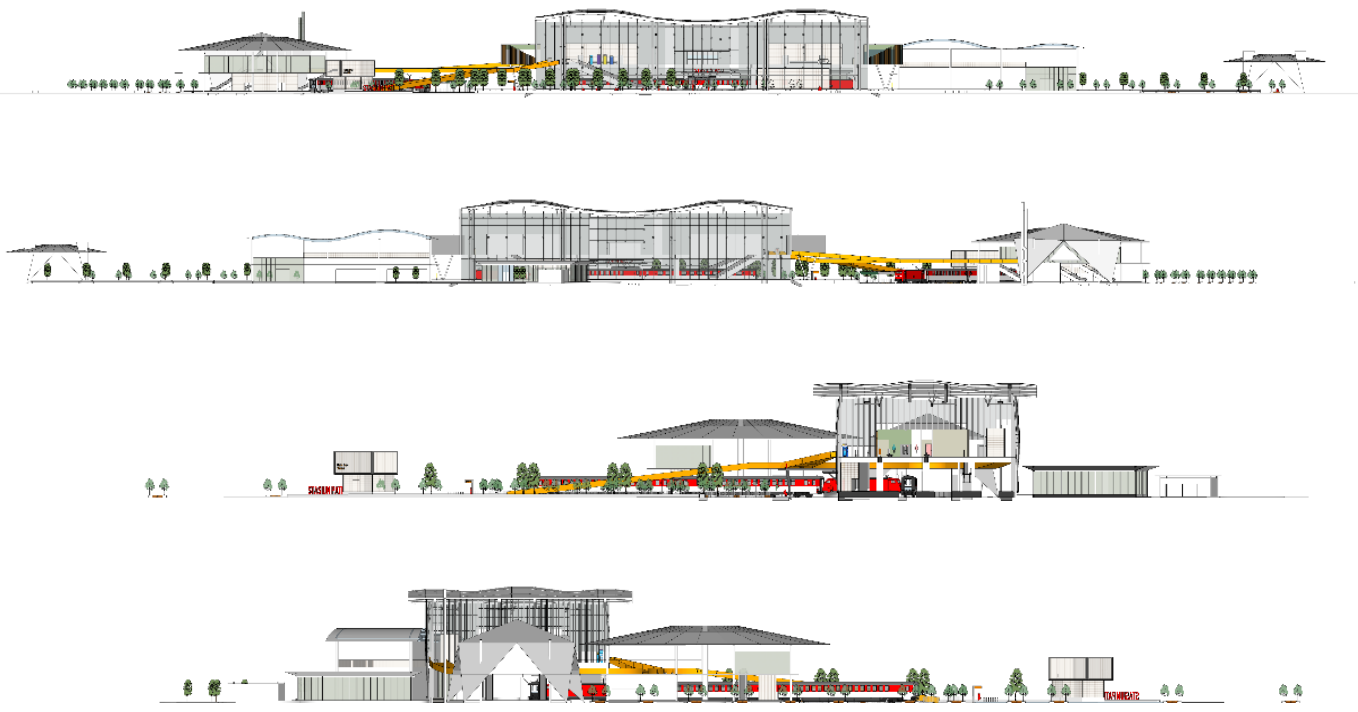

Gambar 10. Tampak Kawasan Stasiun

Sumber: Aziz, 2019 


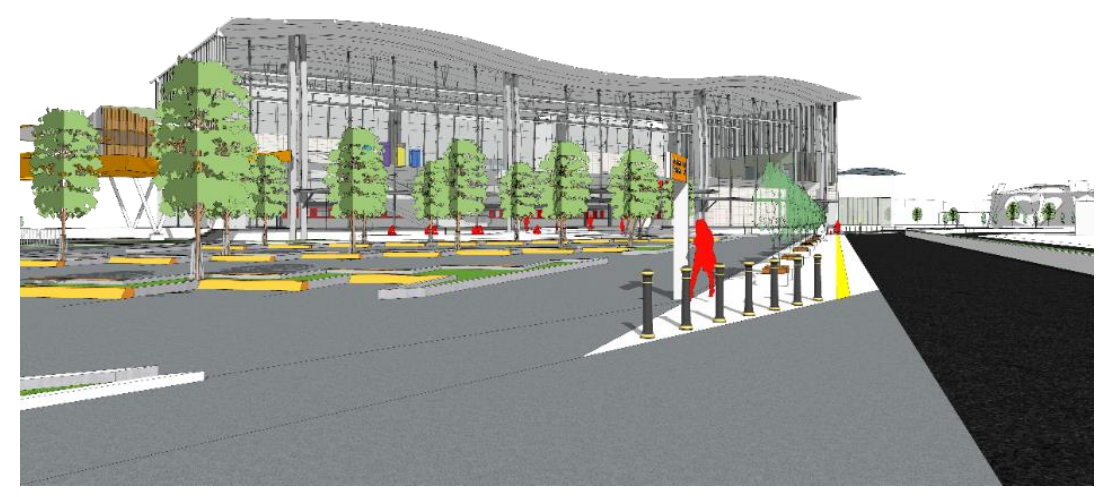

Gambar 10. Perspektif View Mata Manusia Sumber: Aziz, 2019

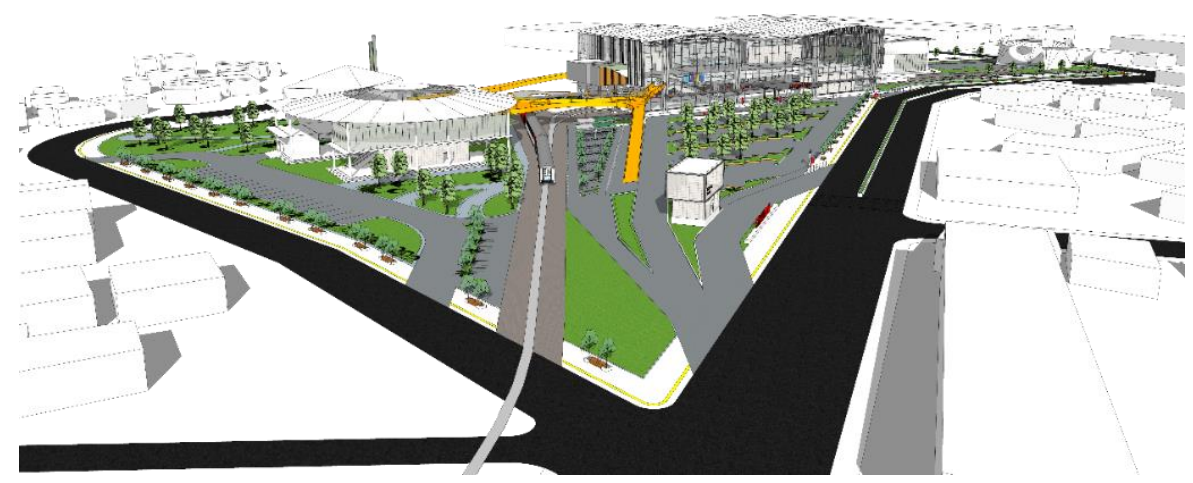

Gambar 11. Perspektif View Mata Burung Sumber: Aziz, 2019

\begin{tabular}{|c|c|}
\hline Parameter & Penerapan Desain \\
\hline Responsive & $\begin{array}{l}\text { Menciptakan ruang yang dapat memunculkan berbagai aktivitas di Ruang Publik } \\
\text { Comfort (Kenyamanan) } \\
\text { - Akses sirkulasi yang mudah, aman, nyaman dan efisien untuk pengunjung } \\
\text { stasiun dengan membedakan akses kendaraan dan akses pejalan kaki. } \\
\text { - } \text { Lebar jalur pejalan kaki yang nyaman dan sesuai standard kebutuhan. } \\
\text { - Kanopi/teduhan saat hujan. } \\
\text { Sitting Area sebagai titik lelah setiap 200-400 meter jalur sirkulasi. } \\
\text { Safety(Keamanan) } \\
\text { - Pagar pembatas untuk anak-anak. } \\
\text { - Suderial perkerasan yang aman walaupun saat hujan (tidak licin) } \\
\text { - Escalator/lift bagi pengguna disabilitas di dalam bangunan }\end{array}$ \\
\hline
\end{tabular}




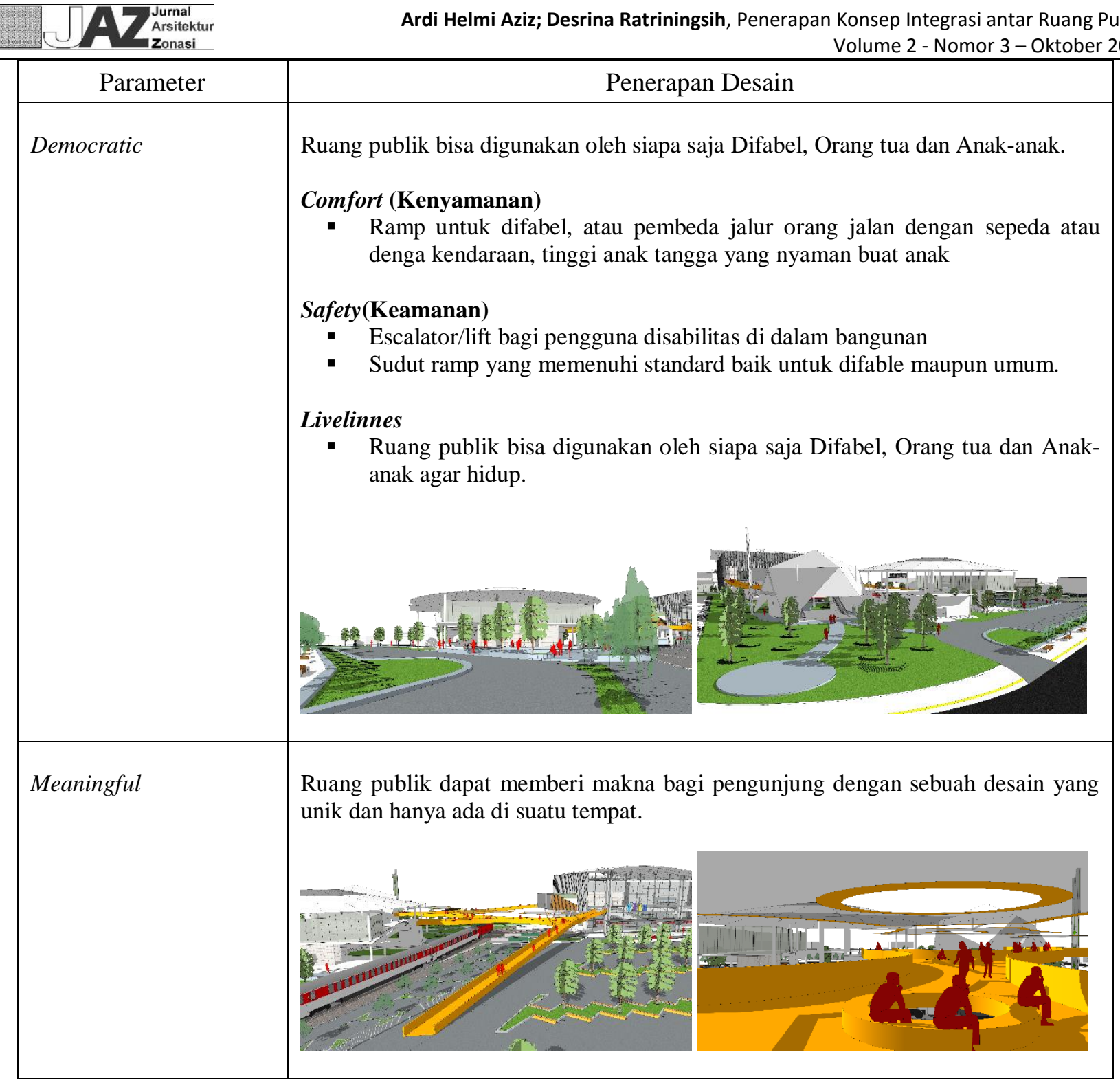

\section{Kesimpulan}

Berdasarkan hasil penerapan konsep pada Redesain Stasiun Kereta Api Pati ini adalah berguna untuk memberikan dampak positif bagi masyarakat Pati dan sekitarnya di masa mendatang, kemudahan yang didapat dalam menggunakan transportasi umum kereta api yang terintegrasi akan mengubah kehidupan masyarakat dari penggunaan kendaraan pribadi ketika berangkat kerja, sekolah, dan wisata beralih menggunakan transportasi umum seperti kereta api salah satunya. Konsep Integrasi Antar Ruang Publik pada Redesain Stasiun Kereta Api Pati juga memberikan kemudahan akses untuk difabel bahkan ramah, aman dan nyaman, difabel tidak perlu khawatir ketika berada di stasiun karena sesuai dengan konsep yang dirancang untuk kemudahan dalam segala akses baik sirkulasi, informasi dan digital akan terpenuhi pada rancangan redesain ini.

\section{Ucapan Terima Kasih}

Ucapan terima kasih penulis sampaikan kepada Universitas Teknologi Yogyakarta yang telah memberikan rekomendasi dilakukannya penelitian ini dan segala bantuan lain yang telah diberikan untuk mengembangkan penulisan.

Ucapan terima kasih disampaikan kepada Bappeda Kabupaten Pati yang telah memberikan ijin memperoleh data yang berguna untuk membantu dalam menyelesaikan analisis dan permasalahan perancangan terkait. 


\section{Referensi}

Carmona, Matthew, dkk. (2007). Urban Design Reader. Architectural Press is an inprint of Elsevier Linacre House, Jordan Hill, Oxford OX2 8 DP, UK.

Ditjen Perkeretaapian, K. P. (2011). Rencana Induk Perkeretaapian Nasional 2030. Jakarta: Ditjen Perkeretaapian, Kementrian Perhubungan.

Farida, I., Yudana, G., \& Rini, E. F. (2017). Tingkat Kesesuaian Ruang Publik Dengan Konsep Livable City Di Kota Surakarta. Arsitektura, 15(1), 165. https://doi.org/10.20961/arst.v15i1.11648

Hantono, D., Sidabutar, Y. F. D., \& Hanafiah, U. I. M. (2018). Kajian Ruang Publik Kota Antara Aktivitas Dan Keterbatasan. Langkau Betang: Jurnal Arsitektur, 80. https://doi.org/10.26418/lantang.v5i2.29387

Herutomo, C. (2002). Ruang Publik Kota Dan Pola Komunikasi Warganya. 23-30.

Ischak, M., Setioko, B., \& Gandarum, D. N. (2018). Peran Place Identity Dalam Menciptakan Community Resiliance. Jurnal Arsitektur Zonasi, 1(2), 77-86. https://doi.org/http://10.17509/jaz.v1i2.12254

Kbbi.kemdikbud.go.id. (n.d.). No Title.

Pati, B. P. P. D. K. (2011). Peraturan Daerah Kabupaten Pati Nomor 5 Tahun 2011 Tentang Rencana Tata Ruang Wilayah Kabupaten Pati Tahun 2010 - 2030.

Pati Ingin Jalur KA Semarang-Lasem Dihidupkan Lagi. (2019).

Ratriningsih, D. (2017). Arahan Penataan Kampung Tradisional Wisata Batik. XIII(2), 116-128.

Wirasmoyo, W. (2019). Optimasi Lahan Terlantar Menjadi Ruang Publik Di Kampung Kota; Studi Kasus: Lahan Terlantar Kampung Badran RW. 09, Yogyakarta. Jurnal Arsitektur KOMPOSISI. https://doi.org/10.24002/jars.v11i5.1295 